\title{
The Identification of Bioactive Compounds from Turbinaria ornata (Turner) J. Agaradh and Computational Studies
}

\section{S. Deepa*, K. Sujatha, D Velmurugan}

\section{S. Deepa*, K. Sujatha, D Velmurugan}

Department of Pharmaceutical Chemistry, Faculty of Pharmacy, Sri Ramachandra University, Chennai, INDIA.

\section{Correspondence}

\section{S. Deepa}

Assistant Professor, Department of Pharmaceutical Chemistry, Faculty of Pharmacy, Sri Ramachandra University, Chennai, INDIA.

E-mail: deepaselvarajs@gmail.com History

- Submission Date: 21-03-2019

- Review completed: 10-05-2019;

- Accepted Date: 30-05-2019.

DOI : 10.5530/pj.2019.11.140

Article Available online http://www.phcogj.com/v11/i5

\section{Copyright}

(C) 2019 Phcogj.Com. This is an openaccess article distributed under the terms of the Creative Commons Attribution 4.0 International license.

\begin{abstract}
Aim/Background: The present work was carried out to identify some of the bioactive components present in the Brown seaweed Turbinaria ornata by GC-MS technique, and to ascertain its medicinal properties. Materials and Methods: GC-MS analysis of some of the potent volatile constituents present in the pet ether of Turbinaria ornata was performed. MD simulations were performed for complex structures of human secretory PLA2 and P38 kinase. GC-MS chromatogram showed peaks indicating the presence of various compounds of interest. The interpretation of the mass spectrum of GC-MS was done using the Database of Indian Institute of Crop Processing Technology (IICPT). Twenty compounds were identified in pet ether extract of Turbinaria ornata. All 20 compounds were screened using PASS online activity prediction server, for the possession of anti-inflammatory potency and the selected target proteins were subjected to molecular docking studies. MD simulations were also performed for the top listed compound 16 which was identified from D3P extract (2,3-Diphenylcyclopropyl)methyl phenyl sulfoxide, trans-). Similarly, the complex structure of PLA2 (phospho-ethanolamine, PE) and P38 kinase (3-(2-pyridine-4-ylethyl)-1H-indole) were simulated for comparative study. Results and Conclusion: Based on the in silico results, the binding affinities for compounds of $\mathrm{T}$. ornata were judged against known standards for its capability to restrain inflammation and to promote possibility for scheming potential antiinflammatory lead from natural compounds were discussed.
\end{abstract}

Key words: Brown algae, T. ornata, GC-MS, Bioactive components, Molecular docking and simulation studies.

\section{INTRODUCTION}

Allergic and inflammatory diseases are the most familiar diseases all around the world. The prevalence, severity, and complexity of these diseases are getting increased rapidly. Although the many synthetic drugs have given rise to remarkable successes in the progress of novel anti-inflammatory and anti-allergic drugs, the continuous use has led to the miscellaneous and objectionable side effects. Meanwhile, the apparent usage of natural products in the management of these diseases has yet to be fully explored. For the last several thousand years, Mankind recognized that marine organisms contain substances accomplished with potent biological activity. Only recently, the serious investigation of seaweeds was started to say, only half a century ago. Currently, vital pharmacological and therapeutic products are being acquired and dynamically sought from the sea. ${ }^{1,2}$ Among the seaweeds, brown algae represent a rich source of many components like laminarins, fucoidans, and also alginic acids. ${ }^{3}$ Moreover, from the ancient time's seaweeds have been used in various fields like medicine, agriculture, etc., ${ }^{4}$ Our present study is focused on the brown seaweed Turbinaria ornata, a widespread species belonging to Phaeophyceae, which is rich in fucoids and sulfated polysaccharides ${ }^{5,6}$ and other components like phlorotannins, flavonoids, tannins, glycosides, etc. Turbinaria ornata has been earlier accounted for its antioxidant, anti-inflammatory, and cytotoxicity activity on murine melanoma and colon cancer. ${ }^{7-9}$ But there have not been many reports on the bioactive components responsible or which supports their biological activity. Hence, the present communication deals with the Gas chromatographyMass spectrometry (GC-MS) analysis of pet ether and chloroform extracts of marine seaweed Turbinaria ornata and molecular docking studies of identified compounds along with known synthetic standard using Schrödinger maestro for its ability to suppress inflammation and to evaluate its antidiabetic potency and further possibility for designing of potential anti-inflammatory and anti-diabetic lead from natural compounds were discussed. Phospholipase A2, human secretory phospholipase A2, and p38alpha MAP kinase are the enzymes focused in this study for the anti-inflammatory activity. These enzymes are the starting material for the inflammatory process which makes it an ideal target for the anti-inflammatory drugs. To the best of our knowledge, this is the first report on GC-MS analysis of pet ether extract of T. ornata and in-silico docking studies of its active constituents. ${ }^{10-12}$

\section{MATERIALS AND METHODS}

The brown seaweed, Turbinaria ornata belongs to Phaeophyceae family was collected from Mandabam district, Tamilnadu. They were cleansed two or three times with sea water followed by fresh water 
to remove debris or intact sand particle. The samples were dried out in the shade and milled in a mechanical grinder to reduce its particle size. About $25 \mathrm{~g}$ of powder was transferred to Schott-Duran bottles and around $250 \mathrm{ml}$ of pet ether in the ratio of 1:10 were added, and the contents of the bottle were stirred continuously at room temperature for two days, and then the extract was filtered, and the solvent is separated by using simple distillation method. The concentrated extract was collected and evaporated at room temperature. It is then submitted to GC-MS examination.

\section{GC-MS Inquisition}

The GC-MS analysis was carried out as per the standard method. ${ }^{10}$ Gas chromatography was done using Perkin-Elmer GC Clarus 500 system and Gas Chromatograph interfaced to a Mass Spectrophotometer (GC-MS) equipped through Elite-5MS fused silica capillary column $(30 \mathrm{~m} \times 0.25 \mathrm{~mm} \times 0.2 \mu \mathrm{m})$ composed of $5 \%$ diphenyl $/ 95 \%$ dimethylpolysiloxane. For GC-MS detection, ionizing energy of $70 \mathrm{eV}$ was used using an electron ionization system. The carrier gas used was Helium gas (99.999\%) at a constant flow rate of $1 \mathrm{ml} / \mathrm{min}$, and $2 \mu \mathrm{l}$ of the sample was injected with a split ratio of $10: 1$; injector temperature was set at $250^{\circ} \mathrm{C}$. The oven temperature was planned from $110^{\circ} \mathrm{C}$ (isothermal for $2 \mathrm{~min}$ ) with a rise of $100^{\circ} \mathrm{C} / \mathrm{min}$ to $200^{\circ} \mathrm{C}$, then $5^{\circ} \mathrm{C} /$ min to $280^{\circ} \mathrm{C}$, ending with a 9 min isothermal at $280^{\circ} \mathrm{C}$. Mass spectra were taken at $70 \mathrm{eV} ; 200^{\circ} \mathrm{C}$ of inlet line source temperature a scanning interval of 0-2 min and mass scan starting from 45 to $450(\mathrm{~m} / \mathrm{Z})$. Entire GC operation time was 36 minutes. The relative \% amount was calculated by matching its peak area to the total areas. To handle mass spectra and chromatogram the Software adopted was Turbo mass (Version 5.2).

\section{Components predicted using GC-MS analysis}

Analysis of both pet ether and chloroform extracts on the mass spectrum was done using the database of Indian Institute of crop processing technology having more than 75,000 patters. GC-MS chromatograms of the extracts represent peaks indicating the presence of an extensive collection of compounds. The spectrum of the unknown component was judged against the spectrum of the known components gathered in the NIST version- the Year 2005 library. The GC- MS chromatogram of D3-P extract was displayed in Figure 1.

\section{Computational methods}

\section{Identification of the target proteins}

We have used the PASS (prediction of activity spectra for substances) server to find the probable target proteins for each of the 20 compounds based on the score. It predicts more than 300 pharmacological effects and enzymatic mechanism base on the structural formula of the compound of interest. It returns a table of biological activities with corresponding probability values. To calculate the activity, we submitted a standard Mol file of each compound drawn using the Chemsketch software.

\section{Steps involved in docking studies}

Molecular docking ${ }^{13}$ and dynamics studies are the procedure by which two molecules mingle together in a $3 \mathrm{D}$ space and are essential tools in structural biology and computer-aided drug design. ${ }^{14-16}$ In this present study, molecular docking was carried out using Schrodinger software, and the simulations were carried out using AMBER software.

\section{Preparation of protein and ligand}

The 3D structure of P38alpha Map kinase (PDB ID: 1W84), human secretory phospholipase A2 from inflammatory exudates (PDB ID: 1POE) and Phospholipase A2 (PDB ID 1FV0) were retrieved from the PDB to validate anti-inflammatory potency of the 20 identified compounds. Using the tool "Protein Preparation Wizard," the above said proteins were prepared for the computational studies. It includes adding hydrogen atoms and atomic charges, removing water molecules, optimization of hydrogen bond network and energy minimization to remove clashes and strained bonds and angles with $0.30 \AA$ RMSD convergence criterion. Addition of hydrogen atoms and correction of bond orders were made for each of the inhibitor presents within the active site without disturbing the bound conformation dictated by the crystal structure. On the other hand, 20 newly identified compounds and the co-crystallized ligands were optimized and performed energy minimization using Ligprep. These Twenty compounds (ligands) were identified by GC-MS interrogation from pet ether extract of T. ornata. The structures of the documented ligand molecules were reclaimed from the PubChem database, and few were drawn using $\mathrm{CHEMSKETCH}$ (ACDLABS 12.0)

\section{Induced fit docking (IFD)}

Based on the PASS biological activity prediction results of the compounds listed in Table 1, it was subjected to XP docking studies using Glide module (Schrodinger suite). ${ }^{17}$ The top listed compounds based on their docking score and glide energy were subjected for IFD to find their mode of interaction with each of the selected target proteins, Phospholipase A2 (1FV0), human secretory phospholipase A2 (1POE) and p38alpha MAP kinase (1W84). The receptor grid was generated based on the actiPhospholipase A2 (1FV0), e site amino acids for docking. We have employed $\operatorname{IFD}(3)$ which introduces the flexibility in both ligand and protein during docking. This was achieved by combining several iterations of docking of the flexible ligand into a rigid receptor followed by the refinement of the active site of the protein to adopt the conformation suitable for a given ligand. In the first step, an ensemble of poses is generated using rigid docking. Next, the sampling of confirmation of protein for each pose generated was in the first step. Third, the re-docking of the ligand into the optimized protein

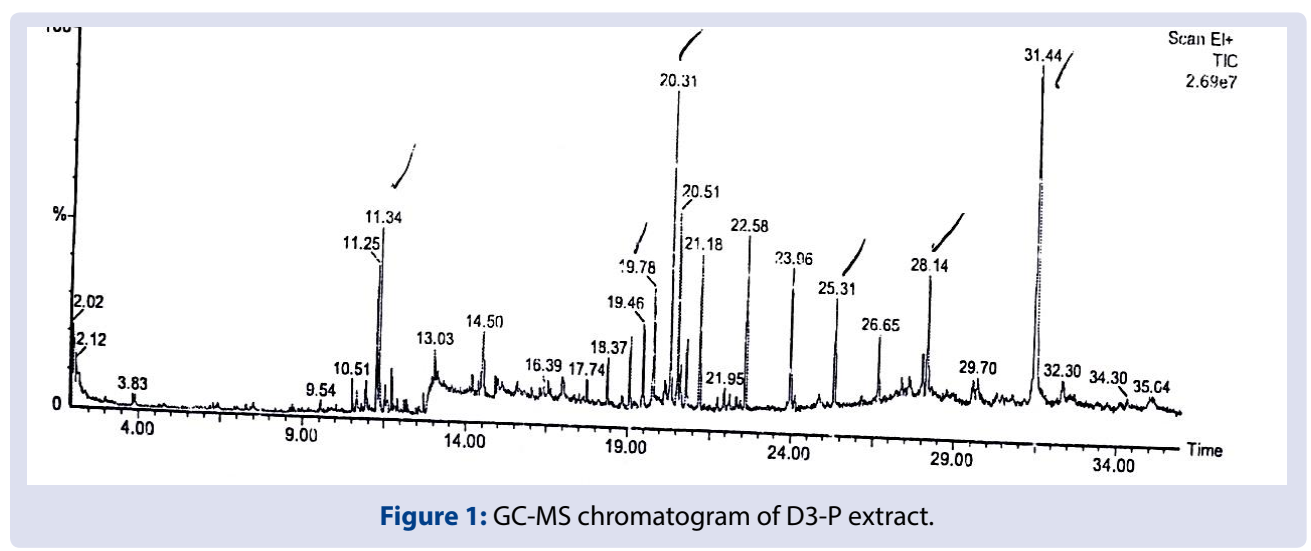


Table 1: Components identified in D3-P extract 432 [GC-MS study].

\begin{tabular}{cclccc}
\hline No. & RT & \multicolumn{1}{c}{ Name of the compound } & Molecular formula & MW & Peak area \% \\
\hline 1 & 3.83 & 3-Methoxy-3-methyl-1-pentene & $\mathrm{C}_{7} \mathrm{H}_{14} \mathrm{O}$ & 114 & 0.32 \\
2 & 7.50 & 2-Propyltetrahydropyran & $\mathrm{C}_{8} \mathrm{H}_{16} \mathrm{O}$ & 128 & 1.23 \\
3 & 9.54 & Dodecane,2-cyclohexyl- & $\mathrm{C}_{18} \mathrm{H}_{36}$ & 252 & 1.59 \\
4 & 10.2 & Heptane,1-nitro & $\mathrm{C}_{7} \mathrm{H}_{15} \mathrm{NO}_{2}$ & 145 & 0.23 \\
5 & 10.51 & Benzene,1,1'-(1,2-cyclobutanediyl)bis-,cis- & $\mathrm{C}_{16} \mathrm{H}_{16}$ & 208 & 1.85 \\
6 & 10.64 & 3,3-Dimethyl-hepta-4,5-dien-2-ol & $\mathrm{C}_{9} \mathrm{H}_{16} \mathrm{O}$ & 140 & 5.89 \\
7 & 10.80 & 2-Undecanethiol,2-methyl- & $\mathrm{C}_{12} \mathrm{H}_{26} \mathrm{~S}$ & 202 & 5.57 \\
8 & 11.34 & 2-Pentadecanone,6,10,14-trimethyl- & $\mathrm{C}_{18} \mathrm{H}_{36} \mathrm{O}$ & 268 & 7.56 \\
9 & 11.90 & Cyclopropanemethanol,2,2-dimethyl-3-(2-methyl-1-propenyl)- & $\mathrm{C}_{10} \mathrm{H}_{18} \mathrm{O}$ & 154 & 2.32 \\
10 & 13.03 & Pentadecanoic acid,2,6,10,14-tetramethyl-,methyl ester & $\mathrm{C}_{20} \mathrm{H}_{40} \mathrm{O}_{2}$ & 312 & \\
11 & 14.50 & Phytol & $\mathrm{C}_{20} \mathrm{H}_{40} \mathrm{O}$ & 296 & 3.65 \\
12 & 19.07 & 1,2-Propanediol,3-benzyloxy-1,2-diacetyl- & $\mathrm{C}_{14} \mathrm{H}_{18} \mathrm{O}_{5}$ & 266 & 15.3 \\
13 & 19.46 & 1-Pentanol,2,2-dimethyl- & $\mathrm{C}_{7} \mathrm{H}_{16} \mathrm{O}$ & 116 & 15.57 \\
14 & 19.78 & Eicosane & $\mathrm{C}_{20} \mathrm{H}_{42}$ & 282 & 9.67 \\
15 & 20.31 & 1,2-Benzenedicarboxylic acid,diisooctyl ester & $\mathrm{C}_{24} \mathrm{H}_{38} \mathrm{O}_{4}$ & 390 & 7.2 \\
16 & 20.51 & (2,3-Diphenylcyclopropyl)methyl phenyl sulfoxide,trans- & $\mathrm{C}_{22} \mathrm{H}_{20} \mathrm{OS}$ & 332 & 4.7 \\
17 & 25.31 & Heptacosane & $\mathrm{C}_{27} \mathrm{H}_{56}$ & 380 & 10.09 \\
18 & 26.65 & Docecane,2,6,10-trimethyl- & $\mathrm{C}_{15} \mathrm{H}_{32}$ & 212 & 4.12 \\
19 & 28.14 & Spiro(androst-5-ene-17,1-cyclobutan)-2'-one,3-hydroxy-,(3a.17a)- & $\mathrm{C}_{22} \mathrm{H}_{32} \mathrm{O}_{2}$ & 328 \\
20 & 31.4 & & $\mathrm{C}_{30} \mathrm{H}_{50} \mathrm{O}$ & 426 \\
\hline
\end{tabular}

Note: $\mathrm{RT}=$ Retention time, $\mathrm{MW}=$ Molecular weight in Dalton

conformation (hence, induced-fit) was carried out. Finally, along with receptor strain and solvation terms, the binding energy associated with each pose was used for scoring.

\section{MD simulations and binding free energy calculation}

The complex structures were simulated for 50 ns each to calculate the binding free energy using MM-GBSA method ${ }^{18}$ and each simulation system was systematically prepared using Leap module of the AMBER10 suite. ${ }^{19}$ The force field parameters for vitamin $\mathrm{E}$, indomethacin and the shortlisted compounds were derived using the antechamber program and general amber force field (GAFF) ${ }^{20}$ The atomic point charges were assigned using the AM1-BCC charge method. ${ }^{21,22}$ Finally, the solute molecule was solvated and energy minimization was performed in two phases using Steepest Descent (SD) and Conjugate Gradient (CG) methods. In the first phase, the solvent molecules were relaxed, and all the atoms of protein were restrained by a harmonic potential with force constant (kcal/mol-Å2) using SD and CG methods. The final phase employs the CG method to relax the whole system with unrestrained protein. The successive equilibration process was divided into two stages. In the first stage, the temperature was stabilized around $300 \mathrm{~K}$ using Berendsen temperature coupling ${ }^{23,24}$ to ensure the canonical ensemble (NVT) of the system with constant volume and with no pressure coupling whereas, in second stage the pressure was stabilized around $1 \mathrm{~atm}$ using isotropic positional scaling with a time constant for pressure coupling, 2 ps with same velocity as first stage. In both the stages, the simulations were run with a time step of $2 \mathrm{fs}$, the bonds involving hydrogen atom were constrained using SHAKE algorithm ${ }^{24}$ and the non-bonded interaction cut-off was set to $10 \AA$. The Particle Mesh Ewald (PME) method ${ }^{25}$ was used to treat the longrange electrostatic interactions. After the equilibration, the system was analyzed in terms of the potential, kinetic and total energy. The ff $03^{26,27}$ all-atom force field was used in all the steps and the binding free energies $\left(\Delta G^{\circ}\right)$ were calculated for all the selected hit molecules using MM-GB/SA. ${ }^{28-30}$ The molsurf ${ }^{31}$ program was employed to compute both the hydrophobic contribution (through SASA) and electrostatic contribution for solvation free energy. The calculation was performed for the last $2 \mathrm{~ns}$ of the trajectory using the mmpbsa.py. ${ }^{32}$

\section{RESULTS}

\section{Gas chromatography and mass spectroscopy (GC-MS)}

The name of the components, its molecular mass, and structures was determined and listed in Table 1.

\section{Molecular docking analysis}

Compound No. 1,2,3,4,6,8,9,10,14,16,18 and 20 were listed to possess activity against Phospholipase A2 (PDB ID 1FV0), Compound No. $1,2,3,4,8,9,10,14,16,17,18,19$ and 20 were listed to possess activity against human secretory phospholipase A2 ( PDB ID: 1POE ) and Compound No. 1,2,3,4,6,8,9,10,14,16,17,18 and 20 were listed to possess activity against p38alpha MAP kinase (PDB ID:1W84).

Docking analysis of components identified in D3-P extract against PDB ID: 1FV0 (Phospholipase A2)

The Docking simulation technique was carried out using Glide module (Schrodinger suite) with the Compound No. 1,2,3,4,6,8,9,10,14,16,18 and 20 against Phospholipase A2 (PDB ID 1FV0) and the Glide docking $\mathrm{XP}$ results were tabulated in Table 2 and the top listed 3 compounds, i.e., Compound No. 16,10 and 18 were subjected to Induced fit docking, the results were positioned in Table 3 and Figure 2. Interactions between Phospholipase A2 (PDB ID: 1FV0) and the ligands are depicted using Pymol and Ligplot. 2(a) and 2(c) depicts binding of CID_16 whereas 2(b) and 2(d) depicts the binding of CID_18, respectively whereas 2(e) and 2(f) depicts Interactions between human secretary PLA2 and Cocrystal. The Ligplot image is generated using Ligplot plus version 1.4.5.

\section{Molecular Docking analysis of components identified in D3-P} extract against PDB ID: 1POE (Human Secretory Phospholipase A2)

Similarly the Docking simulation technique was carried out for the Compounds 1-4,8-10,14, and 16-20 against Human Secretory Phospholipase A2 (PDB ID 1POE) and the Glide docking XP results were tabulated in Table 4 and the top listed 3 compounds, i.e., Compound No. 17, 16 and 18 were subjected to Induced fit docking, the results were positioned in Table 5 and Figure 3: Interactions between human secretary PLA2 and the ligands are depicted using Pymol and 
Table 2: Glide docking XP results of components identified in D3-P extract against phospholipase A2 (PDB ID: 1FV0).

\begin{tabular}{cccc}
\hline S.No & Entry name & Docking score & Glide energy \\
\hline 1 & CID_18.1 & -4.77 & -44.66 \\
2 & CID_16.1 & -6.06 & -36.02 \\
3 & CID_10.1 & -6.89 & -34.64 \\
4 & CID_8.1 & -5.66 & -33.64 \\
5 & CID_14.1 & -4.50 & -31.88 \\
6 & CID_20.1 & -3.59 & -29.80 \\
7 & CID_3.1 & -5.54 & -27.36 \\
8 & CID_4.1 & -2.41 & -21.36 \\
9 & CID_9.1 & -5.18 & -18.98 \\
10. & CID_2.1 & -4.83 & -14.92 \\
11. & CID_6.1 & -4.43 & -14.26 \\
12. & CID_1.1 & -2.81 & -13.92 \\
\hline
\end{tabular}

Table 3: Induced Fit docking results of the top listed components identified in D3P extract against Phospholipase A2 (PDB ID: 1FV0).

\begin{tabular}{|c|c|c|c|c|c|}
\hline S.No & Entry name & Docking score & $\begin{array}{c}\text { Glide energy } \\
\text { (kcal/mol) }\end{array}$ & $\begin{array}{l}\text { Amino acids interacted through } \\
\text { hydrogen bonding }\end{array}$ & $\begin{array}{l}\text { H-bond length } \\
\text { (in } \AA \text { ) }\end{array}$ \\
\hline 1 & CID_16.1 & -10.14 & -52.35 & ASP49 & 3.1 \\
\hline 2 & CID_10.1 & -6.18 & -45.55 & - & - \\
\hline 3 & CID_18.1 & -6.56 & -44.34 & $\begin{array}{l}\text { GLY30 } \\
\text { HIS48 } \\
\text { ASP49 }\end{array}$ & $\begin{array}{l}2.8 \\
2.8 \\
2.8\end{array}$ \\
\hline 4 & Co-Crystal & -9.55 & -54.45 & $\begin{array}{l}\text { TRP31 } \\
\text { LYS69 } \\
\text { GLY30 }\end{array}$ & $\begin{array}{c}3.0 \\
3.0,3.1 \\
3.4\end{array}$ \\
\hline
\end{tabular}

Table 4: Glide docking XP results of components identified in D3-P extract against human secretory phospholipase A2 (PDB ID: 1POE).

\begin{tabular}{|c|c|c|c|c|c|}
\hline S.No & Entry name & Docking score & $\begin{array}{l}\text { Glide energy } \\
\text { (kcal/mol) }\end{array}$ & $\begin{array}{l}\text { Amino acids interacted through hydrogen } \\
\text { bonding }\end{array}$ & $\begin{array}{l}\text { H-bond length } \\
\text { (in } \AA \text { ) }\end{array}$ \\
\hline 1 & CID_16.1 & -10.14 & -52.35 & ASP49 & 3.1 \\
\hline 2 & CID_10.1 & -6.18 & -45.55 & - & - \\
\hline 3 & CID_18.1 & -6.56 & -44.34 & $\begin{array}{l}\text { GLY30 } \\
\text { HIS48 } \\
\text { ASP49 }\end{array}$ & $\begin{array}{l}2.8 \\
2.8 \\
2.8\end{array}$ \\
\hline 4 & Co-Crystal & -9.55 & -54.45 & $\begin{array}{l}\text { TRP31 } \\
\text { LYS69 } \\
\text { GLY30 }\end{array}$ & $\begin{array}{c}3.0 \\
3.0,3.1 \\
3.4\end{array}$ \\
\hline
\end{tabular}

Table 5: Induced Fit docking results of the top listed components identified in D3-P extract against human secretory phospholipase A2 (PDB ID: 1POE).

\begin{tabular}{|c|c|c|c|c|c|}
\hline S.No & Entry name & Docking score & Glide energy & $\begin{array}{l}\text { Amino acids interacted through } \\
\text { hydrogen bonding }\end{array}$ & H-bond length \\
\hline 1 & CID_17.1 & -6.33 & -54.21 & Nil & Nil \\
\hline \multirow{3}{*}{3} & \multirow{3}{*}{ CID_18.1 } & \multirow{3}{*}{-5.42} & \multirow{3}{*}{-47.78} & ASP49 & 3.1 \\
\hline & & & & GLY29 & 2.6 \\
\hline & & & & HIS27 & 2.8 \\
\hline \multirow{4}{*}{4} & \multirow{4}{*}{ Co-Crystal } & \multirow{4}{*}{-12.60} & \multirow{4}{*}{-71.73} & GLY31 & 3.0 \\
\hline & & & & LYS62 & 2.9 \\
\hline & & & & ASP48 & 2.7 \\
\hline & & & & HIS47 & 2.6 \\
\hline
\end{tabular}

Ligplot. 3(a) and 3(c) depicts binding of CID_16 whereas 3(b) and 3(d) depicts the binding of CID_18, respectively whereas 3(e) and 3(f) depicts Interactions between human secretary PLA2 and Co-crystal.

\section{Molecular Docking analysis of components identified in D3-P} extract against PDB ID: 1W84 (Human P38 Alpha map kinase)

The same list of components which was screed in PASS server for antiinflammatory activity (Compounds 1-,4,6,8-10,14,16-18 and 20) were also Docked with Human P38 Alpha map kinase (PDB ID 1 W84), and the Glide docking XP results were tabulated in Table 6 and the top listed 3 compounds, i.e., Compound No. 16,18 and 17 were subjected to Induced fit docking, the results were positioned in Table 7 and the pymol interaction view and Ligplot image of CID_16 was put on view in Figure: 4 (a) and 4 (c) and CID_ 18 on Figure 4 (b) \& 4 (d) and its cocrystal attached with selected protein (PDB ID: 1W84) was displayed in Figure 4 (e) \& 4 (f).

\section{Molecular dynamics simulation study}

Since the percentage peak area of the compound no: 16 is more (10.09) than compound No: 18 (0.32) among the list identified in the D3- P 


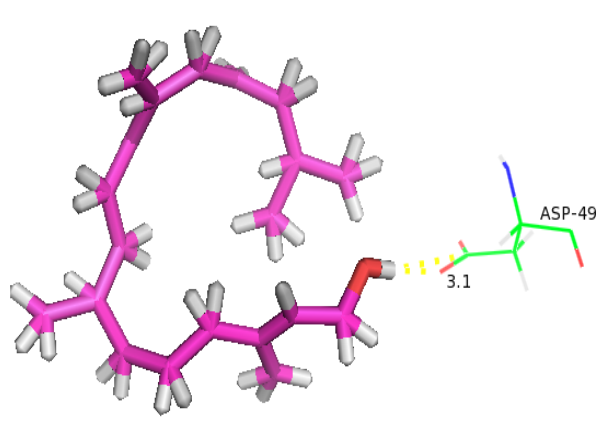

$2 \mathrm{~A}$

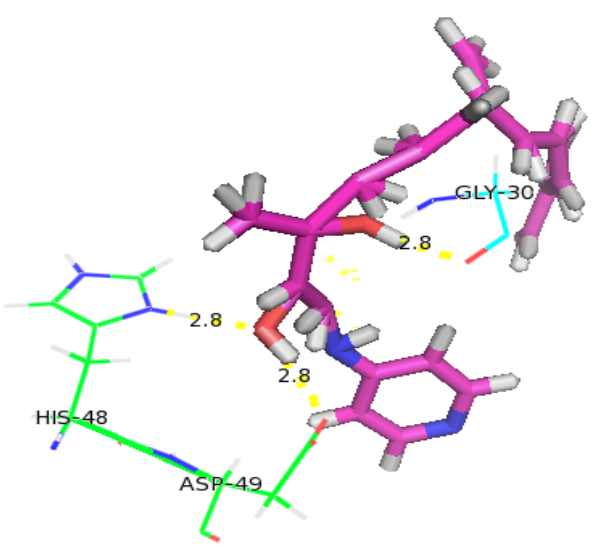

2B

PDB ID: $1 \mathrm{FV0}$

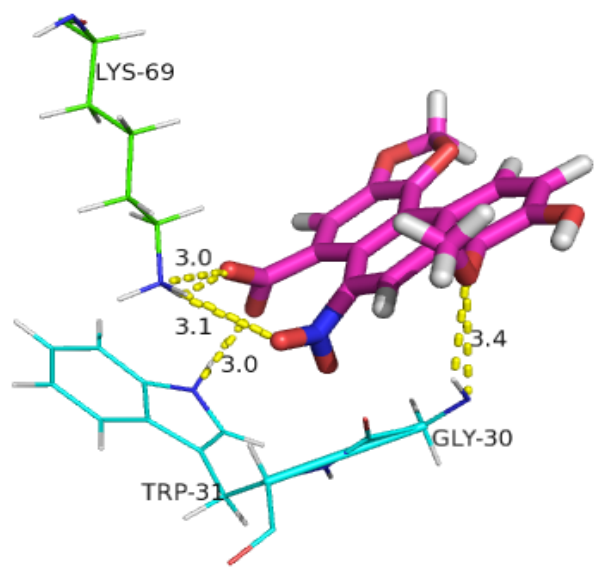

$2 \mathrm{E}$

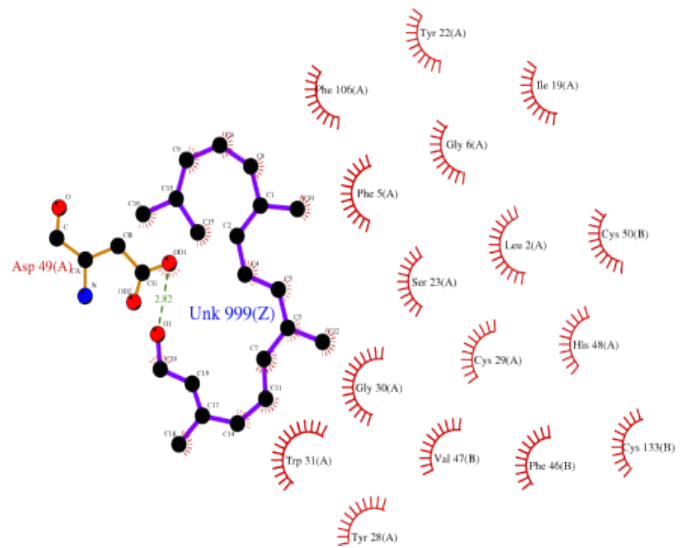

$2 \mathrm{C}$

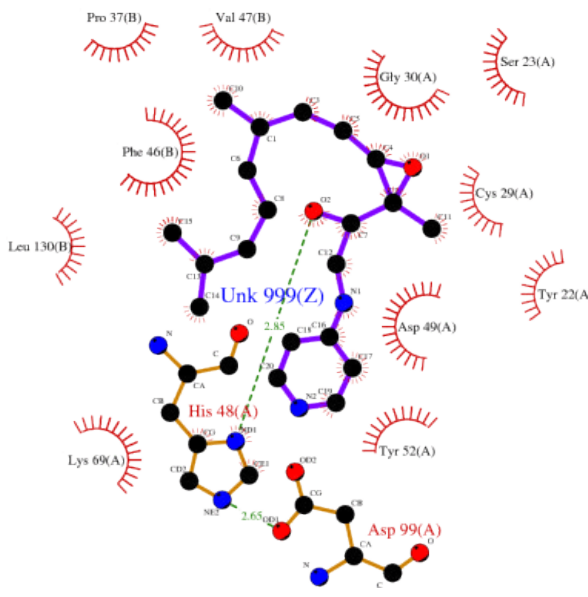

$2 \mathrm{D}$

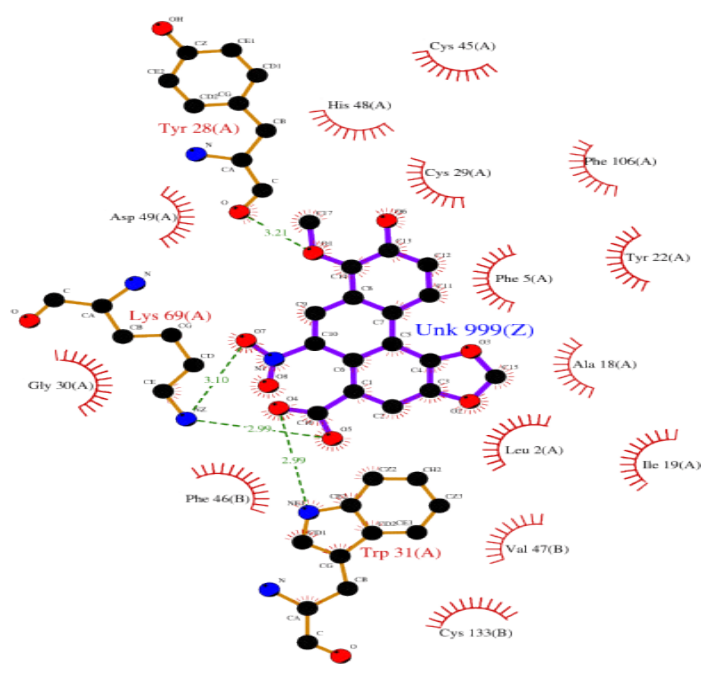

$2 \mathrm{~F}$

Figure 2: Interactions between Phospholipase A2 (PDB ID: 1FV0) and the ligands are depicted using Pymol and Ligplot. A and C depicts binding of CID_16 whereas B and D depicts the binding of CID_18 respectively and E and F depicts binding of PLA2 and Co-crystal. 


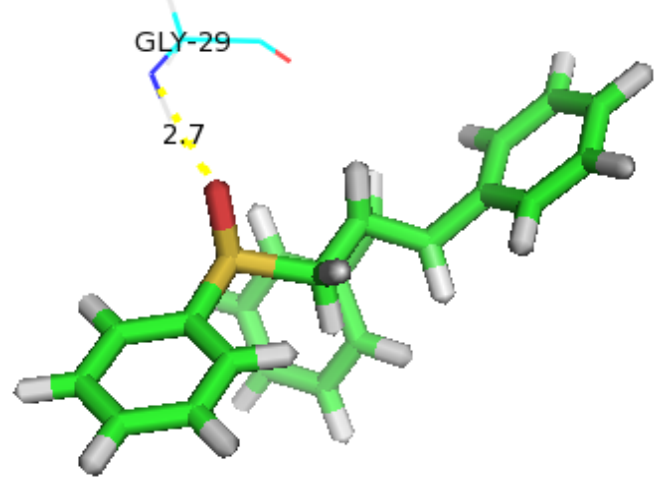

$3 \mathrm{~A}$

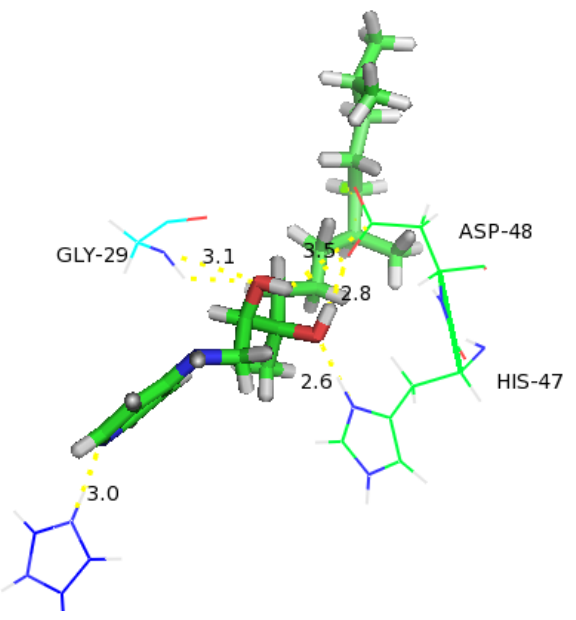

3B

PDB ID: 1POE

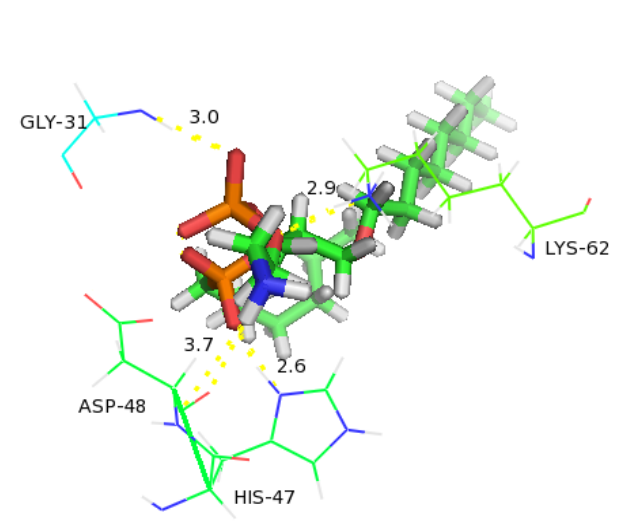

$3 \mathrm{E}$

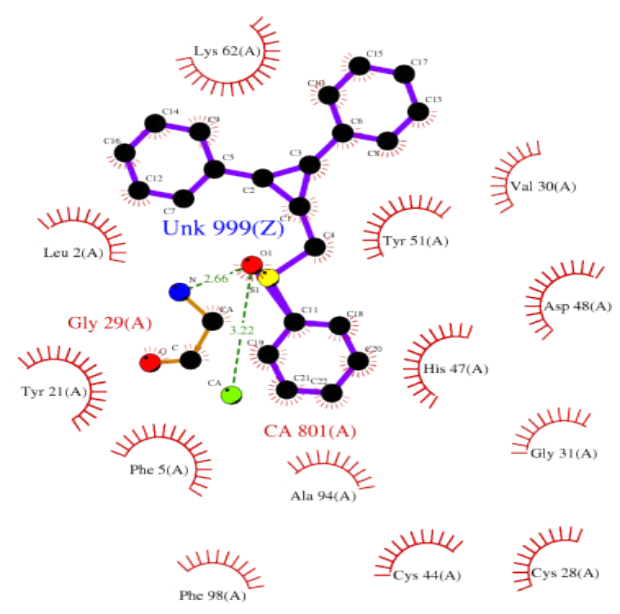

$3 \mathrm{C}$

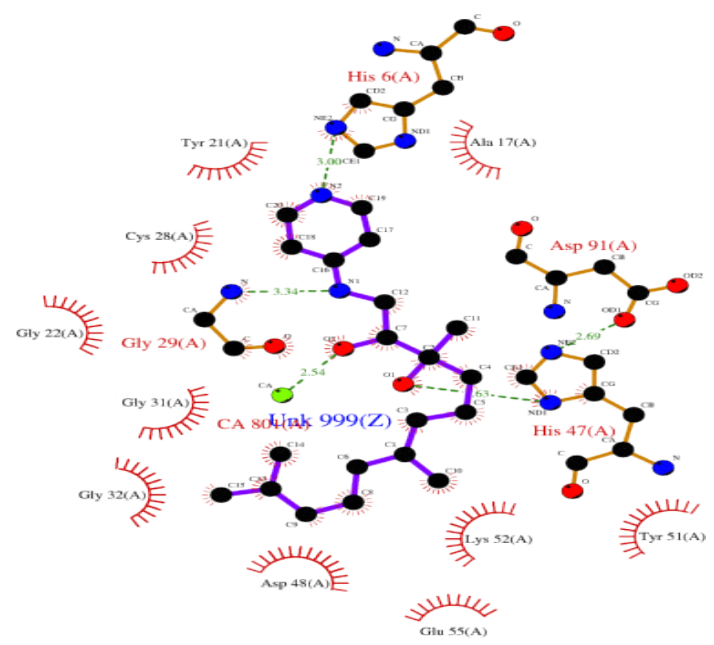

$3 \mathrm{D}$

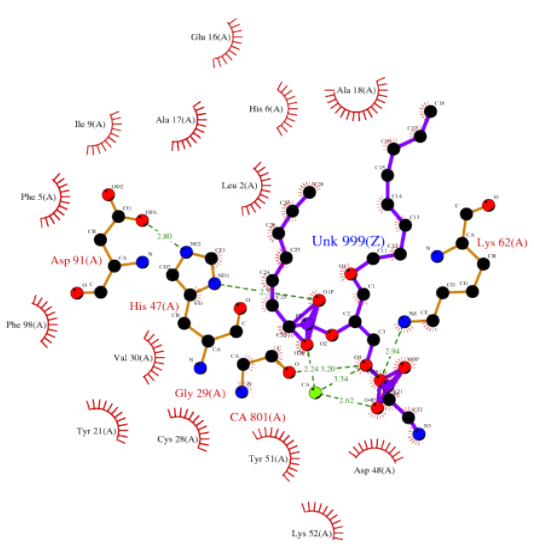

$3 \mathrm{~F}$

Figure 3: Interactions between human secretary PLA2 and the ligands are depicted using Pymol and Ligplot. A and C depicts binding of CID_16 whereas $B$ and D depicts the binding of CID_18, respectively E and F depict binding of human secretary PLA2 and Co-crystal. 


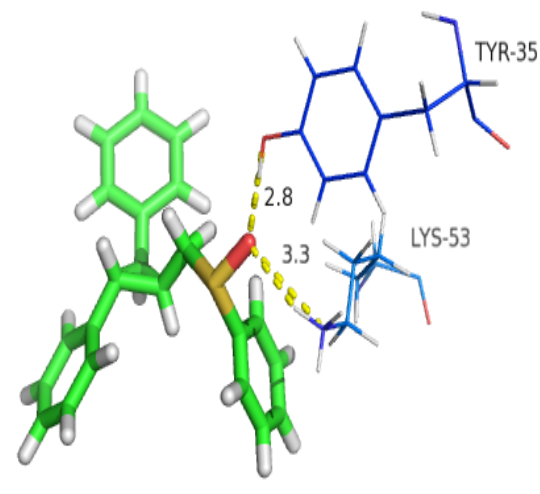

$4 \mathrm{~A}$

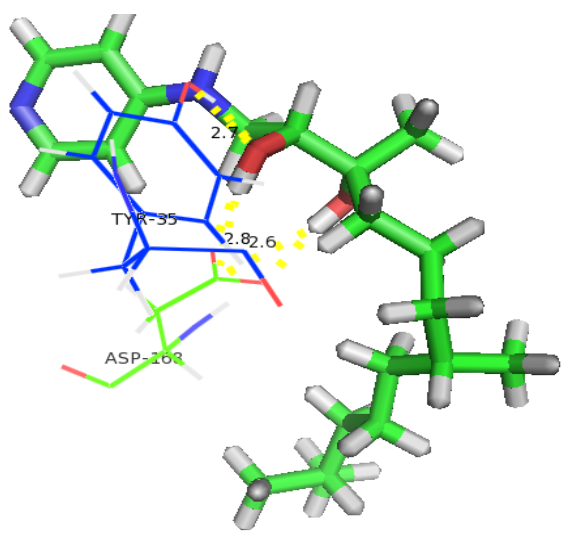

4B

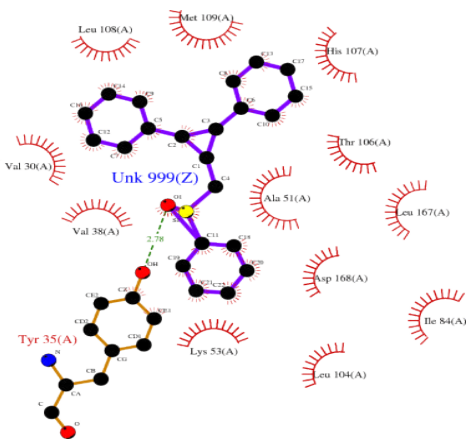

$4 \mathrm{C}$

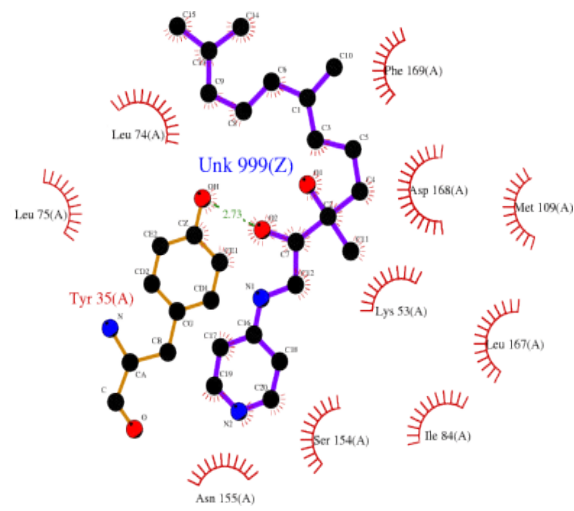

$4 \mathrm{D}$

PDB ID: $1 \mathrm{~W} 84$

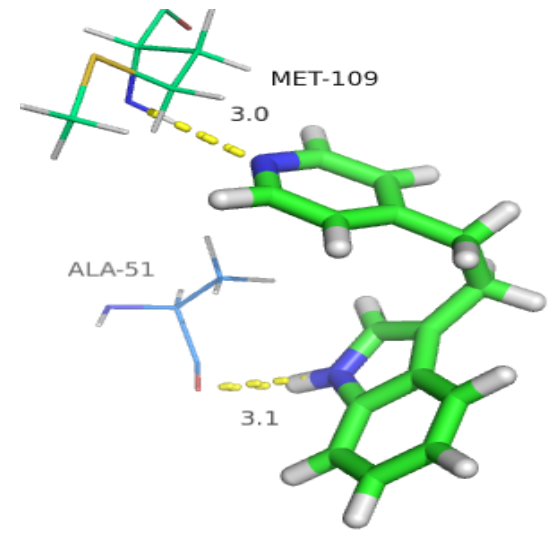

$4 \mathrm{E}$

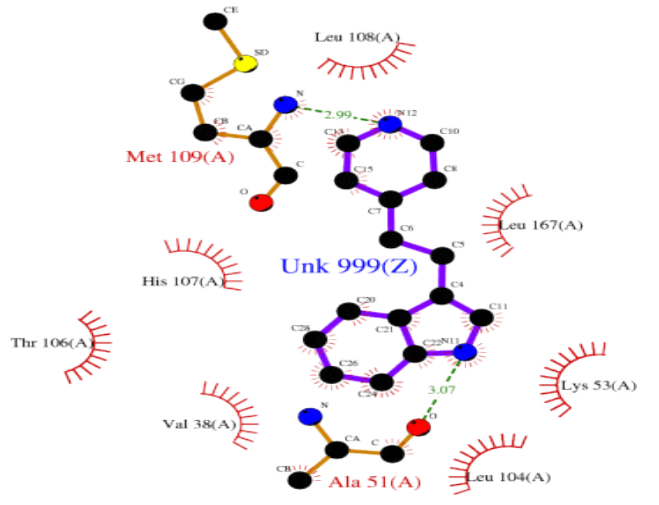

ville

Figure 4: Interactions between Human P38 Alpha map kinase and the ligands are depicted using Pymol and Ligplot. A and C depicts binding of CID_16 whereas B and D depict the binding of CID_18 respectively. $E$ and F depict binding of Human P38 Alpha map Kinase and Co-crystal. 
Table 6: Glide docking XP results of components identified in D3-P extract against human P38 Alpha map kinase (PDB ID: 1W84).

\begin{tabular}{cccc}
\hline S.No & Entry name & Docking score & Glide energy \\
\hline 1 & CID_18.1 & -5.56 & -36.01 \\
2 & CID_16.1 & -5.04 & -35.32 \\
3 & CID_20.1 & -4.30 & -27.65 \\
4 & CID_9.1 & -3.59 & -20.47 \\
5 & CID_17.1 & -3.44 & -37.29 \\
6 & CID_8.1 & -3.42 & -30.39 \\
7 & CID_6.1 & -3.26 & -11.54 \\
8 & CID_3.1 & -3.14 & -23.76 \\
9 & CID_10.1 & -3.05 & -30.79 \\
10 & CID_2.1 & -2.97 & -15.72 \\
11 & CID_4.1 & -2.34 & -20.09 \\
12 & CID_1.1 & -2.31 & -14.35 \\
13 & CID_14.1 & -1.81 & -22.36 \\
\hline
\end{tabular}

Table 7: Induced Fit docking results of the top listed components identified in D3-P extract against human P38 alpha map kinase (PDB ID: 1W84).

\begin{tabular}{cccccc}
\hline S.No & Entry name & Docking score & Glide energy & $\begin{array}{c}\text { Amino acids interacted } \\
\text { through hydrogen bonding }\end{array}$ & H-bond length \\
\hline 1 & CID_16.1 & -6.71 & -49.72 & TYR35 & 2.8 \\
LYS53 & TYR35 & 2.3 \\
2 & & & & ASP103 & 2.6 \\
3 & CID_18.1 & -6.75 & -46.03 & Nil & Nil \\
4 & CID_17.1 & -4.61 & -42.00 & MET109 & 3.0 \\
\hline
\end{tabular}

extract, Compound no: 16 is opted to perform molecular dynamics study. Hence MD simulations were performed for complex structures of human secretory PLA2 and P38 kinase with the compound 16 which was identified from D3P extract (2,3-Diphenylcyclopropyl) methyl phenyl sulfoxide, trans-). Similarly, the complex structure of PLA2 (phospho-ethanolamine, PE) and P38 kinase (3-(2-pyridine-4ylethyl)-1H-indole) were simulated for comparative study. Analyses of trajectories revealed the enzymes are more stable in their complex form with the compound 16 in comparison with the respective cocrystallized compounds. It was observed from Figure $5 \mathrm{rmsd}$ as the root mean square deviation (r.m.s.d) calculated for each trajectory confirms (Figure $5 \mathrm{rmsd}$ ). It shows that the compound 16 binds more stable and also it has a better binding preference to the human sPLA2. Similarly, the differences can be observed in the positional fluctuation (normalized for better comparison) calculation for each residue of the enzyme (Figure 6). The calcium binding loop and a surface loop of PLA2 show more fluctuation in PE bound state whereas it is ordered while compound 16 binds. Similarly, binding of compound 16 shows significantly fewer fluctuations in the loops of p38k. Particularly, the DFG/activation loop shows a large difference in fluctuation in comparison to the binding of the co-crystallized ligand. Together, the results confirm that the compound 16 binding both PLA2 and p38k with more affinity compared to the respective co-crystallized ligands. Further analyses based on the binding free energy $\left(\Delta G^{\circ}\right)$ also substantiates the above observations. Figure 7 clearly shows that the compound 16 binds more stable.

\section{DISCUSSION}

The crude powder was extracted with the solvent Pet ether, and the extract was analyzed using GC-MS technique to get out of the list of the pet ether soluble constituents among which some of the components are with excellent anti-inflammatory activity based on literature review. It is also confirmed by submitting the list of components in the PASS
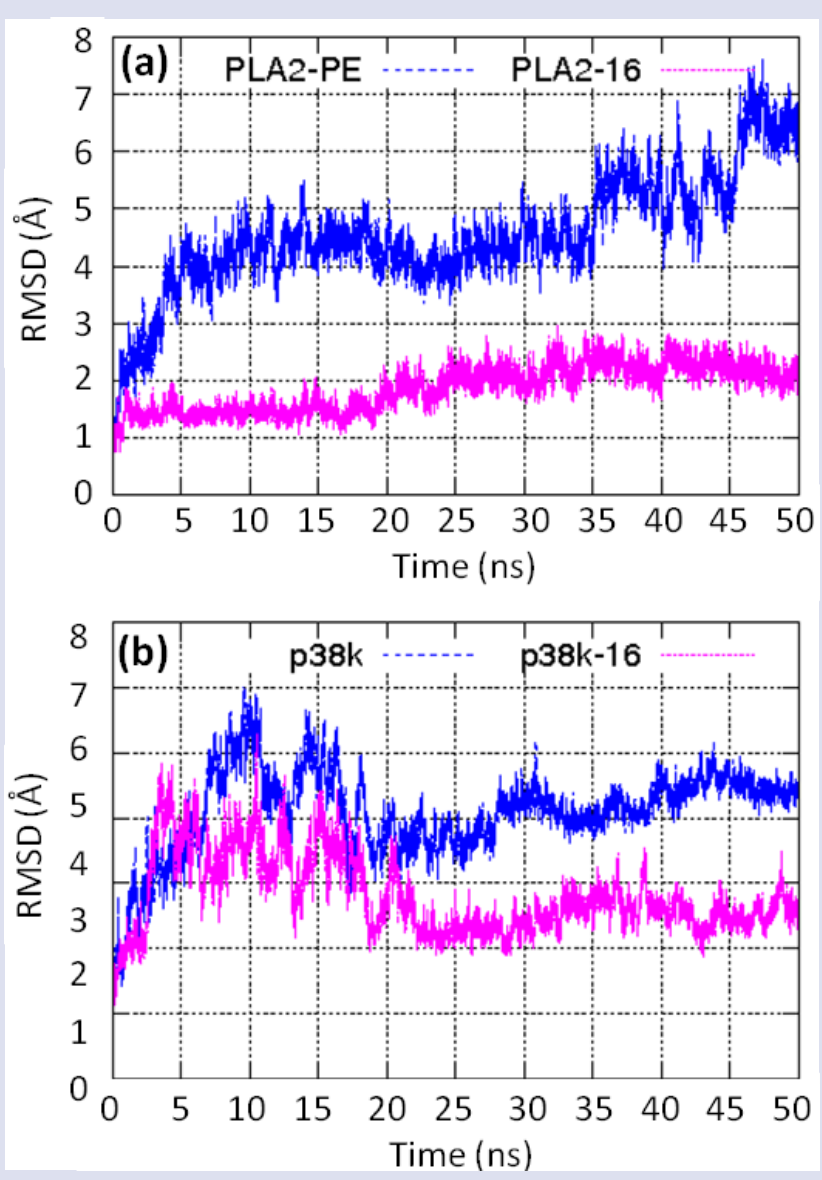

Figure 5: Confirmational changes observed with respect to binding of compound 16 in comparison with the co-crystallized ligand. 

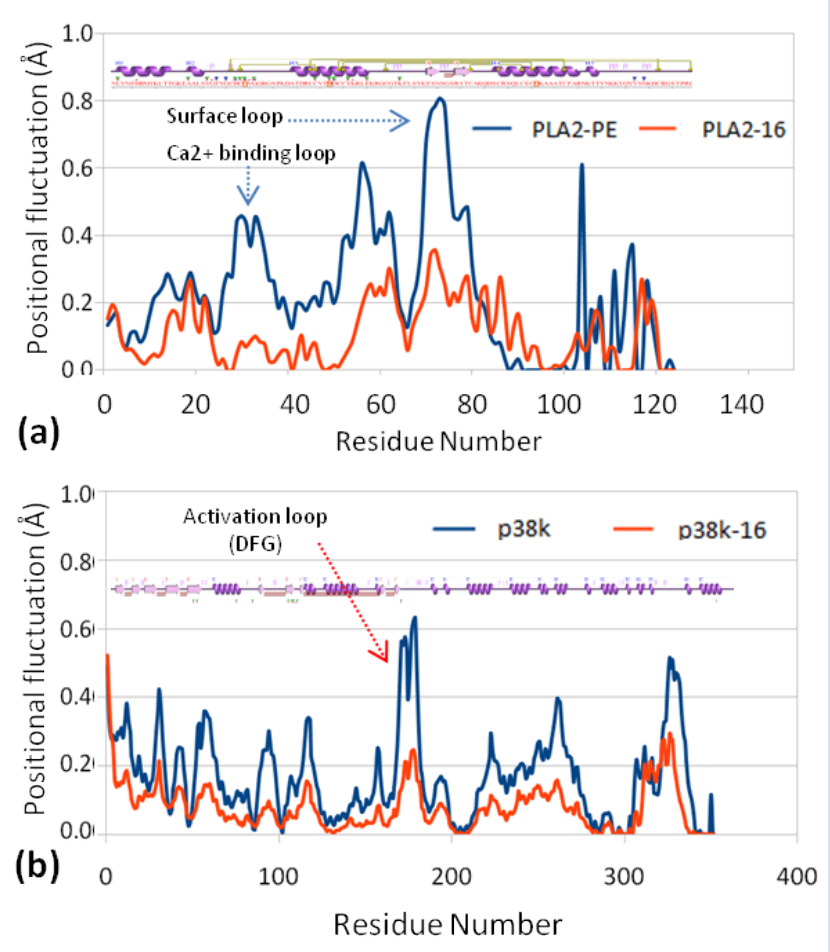

Figure 6: Confirmational changes observed with respect to binding of compound 16 in comparison with the co-crystallized ligand.

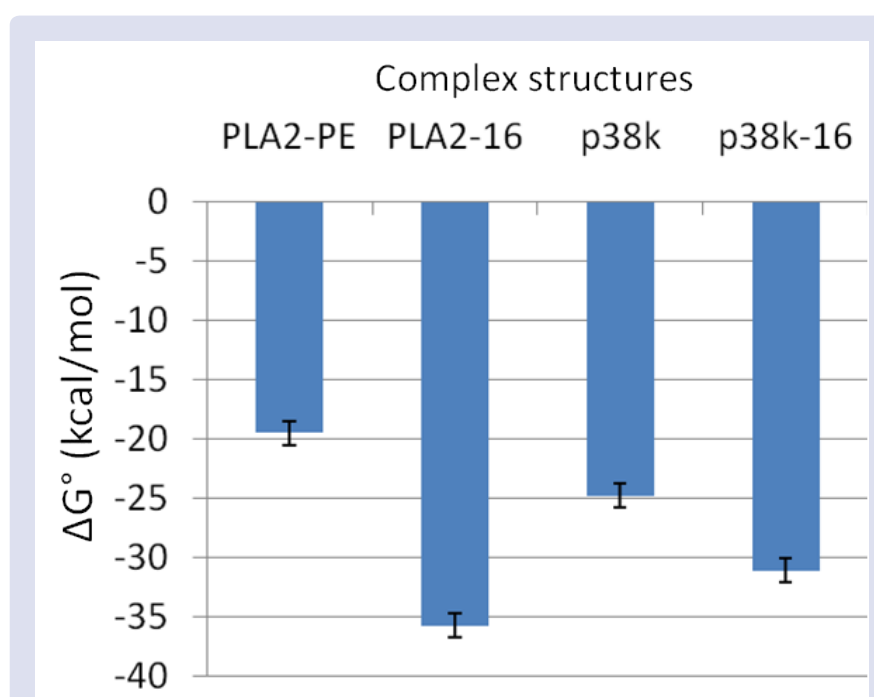

Figure 7: Binding free energy calculated for binding of co-crystallized ligands and the compound 16.

server for its activity affirmation. These components were docked against anti-inflammatory targets using the software; Schrodinger aided drug design software, Maestro. The results of the GC-MS analysis and its chromatogram were exposed in Table 1 and Figure 1 respectively. The results of the interaction between the ligands and protein are shown in pymol and lipgloss view. Glide docking Xp results of the constituents identified in the D3-P extract against PDB ID: 1FV0 showed that compound 18,16 and ten were having good docking score and Glide energy. Hence, therefore, they were subjected to induce fit Docking (IFD). The results of IFD were calculated based on the Number of $\mathrm{H}$ - bond interaction including the amino acid interacted through hydrogen bonding, H-bond length (in $\AA$ ) along with Docking score and Glide energy and compared with the standard compound / co-crystal bound within the selected protein. Accordingly, compound: 16: (2,3-Diphenylcyclopropyl)methyl phenyl sulfoxide, trans- which has close Glide energy and Docking score of about -52.35 and -10.14 when compared with the standard values of -54.45 and -9.55 and also the hydrogen bond length of compound 16: (2.8 in $\AA$ ) with GLY-30 amino acid found to be closer than the standard co-crystal hydrogen bond length (3.4) with the same amino acid.

Similarly in the case of D3P extract components against Human Secretory Phospholipase A2 (PDB ID: 1POE) compound no: 16, 18 and 17 are top listed based on their docking score and glide energy. Henceforth they submitted for IFD against the same target. The result revealed that Compound 18: Docecane,2,6,10-trimethyl- has good affinity with the target Human Secretory Phospholipase A2, since its Glide energy and Docking score of the compound 16 are -47.78 and -5.428716 and values of co-crystal are -71.73 and -12.60 , respectively. The hydrogen bond length with amino acid HIS-47 is 2.9 for compound 16 and 2.6 for co-crystal. Although the same constituents were also docked with another inflammatory target Human P38 Alpha map kinase with PDB ID: 1W84. This time also the same three top listed compounds Compound 16, 17 and 18 were submitted for IFD, but Compound 17: Heptacosane which was shortlisted in the XP results but its Induced fit docking results didn't show any interaction with the amino acid in which co-crystal had.

Thus compound:16: (2,3-Diphenylcyclopropyl)methyl phenyl sulfoxide, trans- and Compound 18: Docecane,2,6,10-trimethyl- which has good interaction with the selected protein with the same amino acid like that of co-crystal may be responsible solely or in combination with other constituents for its anti-inflammatory activity. Although proper in-vitro and in-vivo testing is required for its activity substantiation.

\section{CONCLUSION}

The growing interest in marine-derived anti-inflammatory compounds, along with the development of new technology in marine cultures and extraction will significantly expedite the current exploration of the marine environment for compounds with significant pharmacological applications, which will continue to be a promising strategy and new trend for modern medicine. Future studies on bio-guided fractionation, isolation, and characterization of the selected compounds from these species as well as proper in-vitro and in-vivo testing from these species are needed and are already in process.

\section{ACKNOWLEDGMENTS}

This work was supported by the Faculty of Pharmacy, Sri Ramachandra University, Porur, Chennai.

\section{REFERENCES}

1. Bhadury P, Mohammad BT, Wright PC. The current status of natural products from marine fungi and their potential as anti-infective agents. Journal of Industrial Microbiology and Biotechnology. 2006;33(5):325.

2. Magarvey NA, Keller JM, Bernan V, Dworkin M, Sherman DH. Isolation and characterization of novel marine-derived actinomycete taxa rich in bioactive metabolites. Appl Environ Microbiol. 2004;70(12):7520-9.

3. Shanmugam M, Mody $\mathrm{KH}$. Heparinoid-active sulphated polysaccharides from marine algae as potential blood anticoagulant agents. Current Science. 2000;25:1672-83.

4. Ananthi S, Gayathri V, Chandronitha C, Lakshmisundaram R, Vasanthi HR. Free radical scavenging and anti-inflammatory potential of a marine brown alga Turbinaria ornata (Turner) J. Agardh. 
5. Asari F, Kusumi T, Kakisawa $H$. Turbinaric acid, a cytotoxic secosqualene carboxylic acid from the brown alga Turbinaria ornata. Journal of Natural Products. 1989;52(5):1167-9.

6. Unnikrishnan PS, Suthindhiran K, Jayasri MA. Inhibitory potential of Turbinaria ornata against key metabolic enzymes linked to diabetes. BioMed research international. 2014;2014.

7. Rohfritsch A, Payri C, Stiger V, Bonhomme F. Molecular and morphological relationships between two closely related species, Turbinaria ornata and T. conoides (Sargassaceae, Phaeophyceae). Biochemical Systematics and Ecology. 2007;35(2):91-8.

8. Chattopadhyay N, Ghosh T, Sinha S, Chattopadhyay K, Karmakar P, Ray B. Polysaccharides from Turbinaria conoides: Structural features and antioxidant capacity. Food Chemistry. 2010;118(3):823-9.

9. Hema R, Kumaravel S, Gomathi S, Sivasubramaniam C. Gas chromatographymass Spectroscopic analysis of Lawsonia inermis leaves. Acta Zhengzhou University Overseas Edition. 2010;7(4):48-50

10. Gaddaguti V, Mounika SJ, Sowjanya K, Rao T, Chakravarthy MS, Allu R. GCMS analysis and in silico molecular docking studies of mosquito repellent compounds from Hyptis suaveolens. Int J Bioassays. 2012;1:36-41.

11. Mukund S, Senthilkumar VS. In-silico studies on metabolites of Phormidium fragile against colon cancer EGFR protein. Journal of Algal Biomass Utilization. 2014;5(3):16-22.

12. Sureshkumar $P$, Senthilraja $P$, Kalavathy S. In-silico docking analysis of Calotropis gigantea (L.) R. Br derived compound against anti-cervical cancer activity. World Research Journal of Computer-Aided Drug Design. 2012;1(1):9-12.

13. RCSB Protein Data Bank - RCSB PDB.

14. Preamnath D, Asir RA, Jebamalar JA, GOMEZ JJ. Insilico docking and interaction analysis of bioactive marine compound (sulfated fucose) against the human mutant p53 protein involved in carcinogenesis.

15. Friesner RA, Banks JL, Murphy RB, Halgren TA, Klicic JJ, Mainz DT, et al. Glide: a new approach for rapid, accurate docking and scoring. 1. Method and assessment of docking accuracy. Journal of Medicinal Chemistry. 2004;47(7):1739-49.

16. Halgren TA, Murphy RB, Friesner RA, Beard HS, Frye LL, PollardWT, et al. Glide: a new approach for rapid, accurate docking and scoring. 2. Enrichment factors in database screening. Journal of Medicinal Chemistry. 2004;47(7):1750-9.

17. Sherman $W$, Day $T$, Jacobson MP, Friesner RA, Farid R. Novel procedure for modeling ligand/receptor induced fit effects. Journal of Medicinal Chemistry. 2006;49(2):534-53.

18. Miller III BR, McGee Jr TD, Swails JM, Homeyer N, Gohlke H, Roitberg AE. MMPBSA. py: an efficient program for end-state free energy calculations. Journal of Chemical Theory and Computation. 2012;8(9):3314-21
19. Pearlman DA, Case DA, Caldwell JW, Ross WS, Cheatham IIITE, DeBolt S, et al AMBER, a package of computer programs for applying molecular mechanics, normal mode analysis, molecular dynamics and free energy calculations to simulate the structural and energetic properties of molecules. Computer Physics Communications. 1995;91(1-3):1-41.

20. Wang J, Wolf RM, Caldwell JW, Kollman PA, Case DA. Development and testing of a general amber force field. Journal of Computational Chemistry 2004;25(9):1157-74.

21. Jakalian $A$, Bush $B L$, Jack $D B$, Bayly $C l$. Fast, efficient generation of highquality atomic charges. AM1-BCC model: I. Method. Journal of Computational Chemistry. 2000;21(2):132-46.

22. Yang $Q$, Sharp KA. Atomic charge parameters for the finite difference poissonboltzmann method using electronegativity neutralization. Journal of Chemical Theory and Computation. 2006;2(4):1152-67.

23. Berendsen HJ, Postma JV, van Gunsteren WF, DiNola AR, Haak JR. Molecular dynamics with coupling to an external bath. The Journal of Chemical Physics. 1984;81(8):3684-90.

24. Ryckaert JP, Ciccotti G, Berendsen HJ. Numerical integration of the cartesian equations of motion of a system with constraints: molecular dynamics of n-alkanes. Journal of Computational Physics. 1977;23(3):327-41.

25. Darden T, York D, Pedersen L. Particle mesh Ewald: An N. log (N) method for Ewald sums in large systems. The Journal of Chemical Physics. 1993;98(12):10089-92.

26. Ponder JW, Case DA. Force fields for protein simulations. In Advances in Protein Chemistry. 2003;66:27-85.

27. Duan $Y$, Wu C, Chowdhury S, Lee MC, Xiong G, Zhang W, et al. A pointcharge force field for molecular mechanics simulations of proteins based on condensed-phase quantum mechanical calculations. Journal of Computational Chemistry. 2003;24(16):1999-2012.

28. Wang J, Hou T, Xu X. Recent advances in free energy calculations with a combination of molecular mechanics and continuum models. Current Computer-Aided Drug Design. 2006;2(3):287-306.

29. Wang W, Donini O, Reyes CM, Kollman PA. Biomolecular simulations: recent developments in force fields, simulations of enzyme catalysis, protein-ligand, protein-protein, and protein-nucleic acid noncovalent interactions. Annual Review of Biophysics and Biomolecular Structure. 2001;30(1):211-43.

30. Kollman PA, Massova I, Reyes C, Kuhn B, Huo S, Chong L, et al. Calculating structures and free energies of complex molecules: combining molecular mechanics and continuum models. Accounts of Chemical Research. 2000;33(12):889-97.

31. Connolly ML. Analytical molecular surface calculation. Journal of Applied Crystallography. 1983;16(5):548-58

32. Miller III BR, McGee Jr TD, Swails JM, Homeyer N, Gohlke H, Roitberg AE. MMPBSA. py: an efficient program for end-state free energy calculations. Journal of Chemical Theory and Computation. 2012;8(9):3314-21.

\section{SUMMARY}

Interactions between phospholipase A2 (PDB ID: 1FV0) and human P38 alpha map kinase with the ligand (2,3-Diphenylcyclopropyl) methyl phenyl sulfoxide,trans- to exhibit anti-inflammatory effect of compound identified in the prepared extract using GC-MS technique and results were compared with the co-ligand attached in the selected target.

\section{ABOUT AUTHORS}

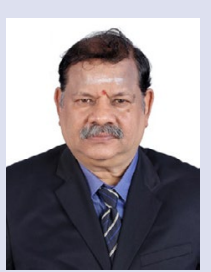

D Velmurugan: Former Head of Centre of Advanced Study in Crystallography and Biophysics and former Dean Research, University of Madras; 33 years of teaching and research experience in the areas of X-ray crystallography - Bioinformatics and Structure based drug design; 10 years of experience in the isolation and characterization of active compounds from herbs; Guided 43 candidates for their Ph.D.s and published 605 research papers so far with more than 580 international publications. Visited many countries as visiting scientist in short terms and had four International collaborative projects. Completed successfully many projects funded by CSIR, DBT,DST and ICMR; Collaborative research activities with Universities in North Eastern Region also. 


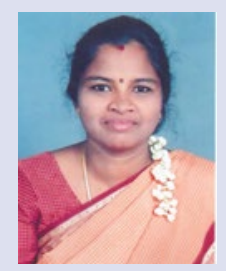

Prof. Dr. K. Sujatha has 22 years of teaching and research experience in SRIHER(DU). She published 20 research papers in International, 20 research papers in National journals and 56 research Papers Presented in various Conferences. She Co-authored a chapter in Nanobiopharmaceutical technology Applications and Perspectives, Elsevier India Private limited, 2014. She is awarded a certificate of appreciation for best research paper in Dr.P.D.Sethi annual award-2011.Currently she is guiding 06 Ph.D Research scholars and her area of interest is synthesis of novel cardiovascular and anti-viral heterocyclics, antidiabetic and anti-viral herbal nanoparticles. She is a life member of IPA and fellow of Indian Chemical Society.

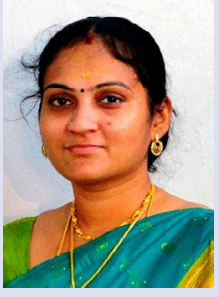

Assistant Prof. Mrs. S. Deepa has 10.5 years of teaching and research experience in SRIHER(DU) including previous experience of 1 year in SRM College of pharmacy. She published 8 research papers in International, 3 research papers in National journals and 11 research Papers Presented in various Conferences and attended more than 28 conferences and workshops including national and international. She guided 10 B.pharm project and 2 UG students -Intramural research projects granted by SRIHER (DU) for Rs. 10,000/- each. She also got received Rs. 200000/- intra mural fund from SRIHER (DU) for carrying out basic research. She is also a coinvestigator in few intramural grants of the same university. Her area of interest is seaweed research and its beneficial effects towards inflammatory bowel disease. She is being serving as a reviewer for various journals.

Cite this article: Deepa S, Sujatha K, Velmurugan D. The Identification of Bioactive Compounds from Turbinaria ornata (Turner) J. Agaradh and Computational Studies. Pharmacog J. 2019;11(5):873-83. 